\title{
PERCEPTION OF GRADUATE STUDENTS ON THE USE OF THE INSTITUTIONAL REPOSITORY OF THE UNIVERSITY FOR DEVELOPMENT STUDIES, TAMALE, GHANA
}

\author{
1'Ibrahim, A. K., ${ }^{1}$ Mohammed, H. \& ${ }^{2}$ Bawa, S. \\ ${ }^{1}$ Library, University for Development Studies, Tamale \\ ${ }^{2}$ Library, Tamale Technical University, Tamale \\ Corresponding Author’s Email: kararaibrahim@gmail.com
}

\begin{abstract}
This study examined the perception of graduate students in the use of the institutional repositories particularly in relation to the institutional repository of the University for Development Studies (UDS), Tamale, Ghana. The study examined the level of students' awareness, attitude towards the IR, level of use and level of satisfaction, and the challenges facing them in their utilisation of the UDS IR. The study adopted the descriptive survey approach and was conducted on the four campuses of the University for Development Studies (UDS) in Wa, Navrongo, Nyankpala and Tamale in May, 2019. A total of 104 copies of a questionnaire were distributed to graduate students based on random sampling and 88 copies of the questionnaire were completed and returned. Only 85 copies were found usable and thus were used for the analysis. The study revealed that $67 \%$ of the respondents were aware of the IR. However, utilization was only occasional among them. The study also revealed that majority (75\%) of graduate students use the IR to access theses and dissertations. The lack of awareness creation about the IR and the inadequate ICT connection and infrastructure were the challenges that hinder effective use of the IR. The study suggests that library orientation should be organised to educate graduate students on the benefits of using the IR for their studies especially in doing research. The study also recommended improvement in ICT infrastructure to ease access to the IR. Do-It-Yourself(DIY) short videos could be put on the IR interface and the Library website to guide students on how to use the IR.
\end{abstract}

\section{Keywords: Institutional Repository, Perception, Graduate students, Utilization, University for}

\section{Development Studies, Ghana}

\section{Introduction}

Access to scientific and scholarly information for graduate students is very critical if the quality of their research is to be enhanced. According to OkiteAmughoro, Makgahlela and Bopape, (2014) the quality of a postgraduate degree is enhanced through the accessibility and utilization by graduate students of the research output of the faculty and students of the parent institution as well as the research output of other institutions. This prevents duplication of research and also ensures that research outcomes are further investigated to draw more valid conclusions.
The provision of these resources has always been the core business of the academic library in most tertiary institutions.

In recent times because of advancements in information communication and technology academic libraries have included the provision of electronic resources and the adoption of institutional repositories as part of their services. Manchu and Vasudevan (2018) define an Institutional repository (IR) as a formally organised and managed collection 
of digital content generated by the faculty, researchers and students at an institution.

The content of an institutional repository is usually made freely available through Open Access a system which allows for free access to scientific and scholarly articles without any hindrance apart from the cost of the internet itself (Nunda and Elia, 2019). Access to the documents on the IR are therefore freely available to anyone who wants to access them and this could be a very good source of scientific and scholarly information for graduate students.

The need to provide scientific, scholarly and timely information to graduate students is further buttressed by Dulle (2011) who asserts that graduate students are being trained to become future researchers and faculty members. It is therefore necessary for the IR to bring such people and the needed information togather. It is also significant to note that the theses and dissertations produced by graduate students often form an important input of institutional repositories. Saulus and Mutula (2019) aver that IRs are particularly important as they were introduced to overcome the high cost of journal subscription faced by libraries as a result of budget cuts, high rate of inflation and currency devaluation especially in developing countries.

A number of research findings have shown that graduate students have a high level of awareness of IRs, however, most of the findings also indicate a low level of usage of IRs by graduate students (Abdelrahman, 2017; Dulle, 2011; Kim, 2007).

The UDS Library has invested significantly in the establishment of an IR in order to provide services to the university community especially graduate students. In order to get the university community to efficiently use the IR the library embarked on a number of activities in the past to market the IR to the university community. However, a study by Thompson, Akeriwe and Aikins (2016) revealed a low level of participation by researchers.

This study has become necessary because with the strategies put in place to market and promote the UDS IR it was expected that the university community including graduate students would patronise the IR.
This study is also undertaken because there is very little literature on the perception of students, particularly graduate students about the IR and their utilization of it. Graduate students usually submit their theses and dissertations to the IR to form the content of the IR. They are therefore key stakeholders in IR and their perceptions about IR are very relevant to IR managers and policy makers.

\section{Brief Background of the UDS Institutional Repository}

The University for Development Studies, Tamale (UDS) is a multi-campus public university setup across three regions in northern Ghana in May 1992 under the Provisional National Defence Council (PNDC) Law 279. The campuses are located in Nyankpala and Tamale in the Northern Region, Wa in the Upper West Region and Navrongo in the Upper East Region.

The UDS institutional repository was established in 2014 and makes available its content on the DSpace software. Documents on the UDS IR are organised into communities and sub-communities which are further sub-divided into collections for easy browsing. There are ten (10) communities which include fifty-nine (59) collections. The names of the contributing authors are shown with the corresponding number of their academic production deposited in the repository. These names are sorted in ascending order based on the author with the most elements in the repository.

\section{Objectives of the Study}

The main objective of this study is to determine the perception of graduate students in the use of institutional repositories with particular reference to graduate students at the University for Development Studies in Tamale, Ghana.

The specific objectives are:

1. To determine if graduate students in UDS are aware of the existence of the Institutional Repository (IR) in the university;

2. To determine the extent of use of the IR by graduate students; 
3. To find out the factors that hinder the use of institutional repositories by graduate students;

\section{Theoretical Framework}

The study was based on the Technology Acceptance Model (TAM), a theoretical framework originally proposed by Davis (1986, as cited in Lee, et. al., 2003) to explain the factors that influence the acceptance or rejection of a technology by individuals. The acceptance or rejection of a technology is often dependent on the perception of how useful and how easy it will be to use. The more the perceived benefits of using the technology the more people will accept the technology. Again, the easier the usage the more people will accept the technology. Conversely, TAM is therefore based on the assumption that the usage of a technology is influenced by the perception of usefulness, perception of ease of use and the attitude of the individual.

The perception of usefulness can be explained as the unsubstantiated view of an individual about how the use of something will improve their work performance. It is also the perception of the potential user that the use of some technology will positively change their job performance (Davis et. al., 1989).
The belief of a person in a system can be influenced by other factors referred to as external variables in TAM. The external factors together with either the Perceived Ease of Use or the Perceived Usefulness influence the attitude toward using the system, the behavioural intention to use the system and the actual use of the system.

If graduate students perceive the institutional repository to be a system that provides information resources that meets their information needs and also easy to navigate without much effort, then they will accept and use it. However, if they do not find the IR relevant in their research and easy to use then they will stay away from using it.

The actual utilization of a system is determined by the behavioural intention which is also influenced by the perceived usefulness of the system acted upon by external variables. An individual will employ a certain technology if his or her perception about the outcome of using it is that it will improve their current state.

The model therefore demonstrates how the expected benefits and the expected ease of use will determine the behavioural intention to use a system and also determine how the individual reacts towards utilizing it.

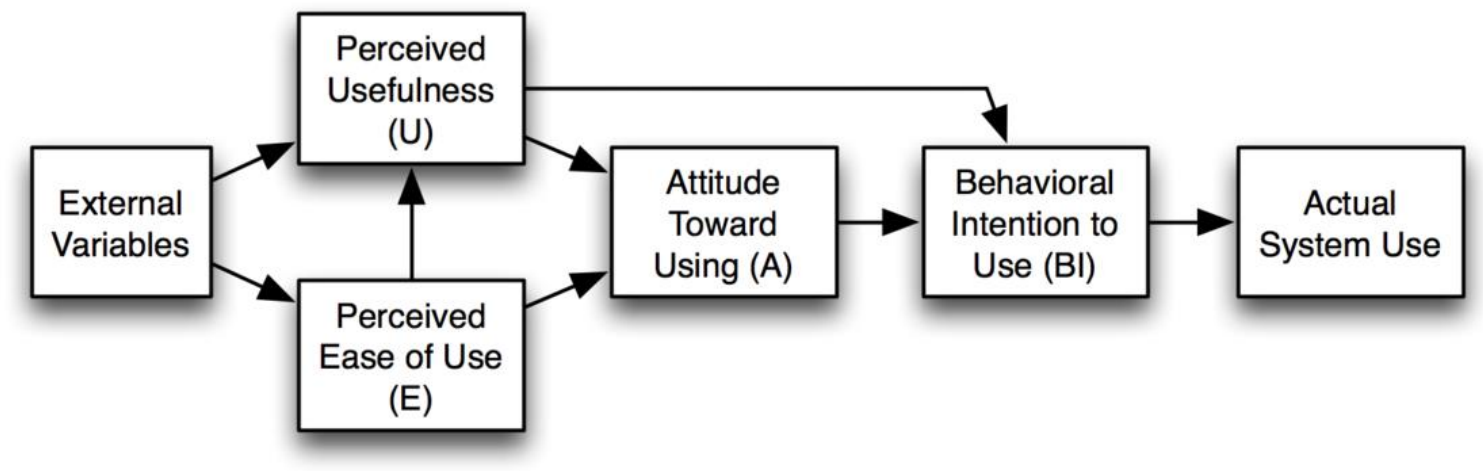

Figure 1: Technology Acceptance Model (TAM) (Davis et al., 1989).

The theory was considered suitable for the study in view of fact that the use of institutional repositories by students is greatly affected by their perception of the services they can get from an IR, as well as their perception of how easy it is to use the technology. A positive perception of the IR or even a good 
experience of it results in an effective use of it and vice-versa. If students perceive that using the institutional repository will improve research and learning, then chances are that they will appreciate and use the IR more.

\section{Literature Review}

Since people will have to know about the existence of something before they can use it the level of awareness of people about the IR is often seen as a factor that determines its usage. In a study of the institutional repositories and open access awareness among the researchers of the University of Calicut, Manchu and Vasudevan (2018) discovered that the majority of researchers in the university were aware of the concept of institutional repositories and saw it as an avenue to improve their scholarly activities. However, they were constrained by how to archive their work in the repository, while some of them thought that publishing in an institutional repository did not give them the level of prestige they needed. Abdelrahman, (2017) investigated the attitudes of graduate students towards the utilization of institutional repository of the University of Khartoum (Khartoumspace) and found that the respondents mostly used electronic theses, dissertations and eBooks among the items on the IR. The study also revealed that although there was low utilization of the IR by the respondents, they have a positive attitude towards the repository, and that the majority of the respondents' source of awareness about the IR is their colleagues rather than a librarian.

The potential role for research students in an institutional repository (IR) was investigated by Pickton and Mcknight (2006) at the Loughborough University on the proposed Loughborough repository and found that students were mostly interested in access to complete theses, postprints and conference papers.

Mnzava, and Chirwa, (2018) in a study on the utilization of the Institutional Repository of the Sokoine University of Agriculture (SUAIR) by the faculty members at the College of Veterinary Medicine and Biomedical Science (CVBMS) in Tanzania discovered that the faculty members had a positive attitude towards the use of the IR but were constrained in its patronage by their busy schedule and the fear of plagiarism.

A study by Okoroma (2018) on the perception and behaviour of faculty members towards institutional repositories in academic libraries in Nigeria also reveals that most of the faculty members in Nigeria are either not conversant with the concept of institutional repositories or are not well informed about the aims and objectives of IR.

The relationship between the level of awareness and the level of faculty members' contribution is further demonstrated in a study by Moseti (2016) who studied the archiving of research documents in universities in Kenya and found that faculty members at universities have individually been involved in archiving their electronic works although they seldom did that through the institutional repository. This has been largely attributed to the lack of awareness of the important role of digital repositories in digital preservation. Mammo and Ngulube (2015) in a study conducted at some selected universities in Ethiopia on the attitudes of academics toward open access journals discovered that the majority of the academics were aware of open access journals, had positive attitude towards open access journals and were willing to use them. The study also reports that the academics were actually using open access journals.

Dlamini and Snyman (2017) in a study of institutional repositories across Africa conclude that the problem of lack of awareness of Open Access Institutional Repositories (OAIRs) is common to most countries in Africa.

Okoroma (2018) conducted a survey of the utilization of institutional repositories (IRs) of five Nigerian universities in terms of self-archiving, preservation of research articles and for searching information resources and found that the IRs faced the problem of low submission of documents. The study also found that although utilization of the IR 
was high faculty members were reluctant to submit their works. The authors therefore suggested the need for education and awareness among faculty members on the importance and use of the IR.

Students have been known to use the institutional repository to search for thesis and dissertations mostly when they are carrying out research for their thesis. This is an important role that the institutional repository plays to facilitate learning and research in an institution. In a study of the role of research students in an institutional repository at the Loughborough University Pickton and Mcknight (2006) finds that students were more interested in having access to complete theses, post prints and conference papers.

\section{Methodology}

The study adopted the descriptive survey approach. The study was conducted on the four campuses of the University for Development Studies (UDS) in Wa, Navrongo, Nyankpala and Tamale in May, 2019. A total of 104 copies of a questionnaire were distributed to graduate students of the UDS based on random sampling and 88 copies of them were completed and returned. Only 85 copies were found usable and thus were used for the analysis.

\section{Results and Discussions}

\section{Awareness and Use of Institutional Repository}

To achieve the first objective of the study the level of awareness of respondents on the existence of the institutional repository was examined and the data are presented in Table 1 below:
Table 1: Level of Awareness of IR

\begin{tabular}{|l|l|l|}
\hline Response & \multicolumn{2}{|l|}{ Students $(\mathrm{n}=85)$} \\
\hline & Freq. & Percentage \\
\hline Yes & 57 & 67 \\
\hline No & 28 & 33 \\
\hline Total & 85 & 100 \\
\hline
\end{tabular}

Source: Field survey, 2019

The results from the table above indicate that 57 $(67 \%)$ of the respondents were aware of the existence of the institutional repository whilst $28(33 \%)$ of the respondents indicated their lack of knowledge about the existence of an IR in the university. The high level of awareness confirms the findings of Manchu and Vasudevan (2018) who found a high level of awareness of IR at the University of Calicut in India. Similarly, Dhanavandan and Tamizhchelvan (2013) discovered that majority of faculty members had a high level of awareness of the IR at the Annamalai University, Tamil Nadu, India. Also, Thompson et. al. (2016) reported a high level of awareness of IR at the University for Development Studies in Tamale, Ghana. However, Ratanya (2017) discovered low level of awareness among faculty members at Egerton University in Kenya. Similarly, Boufarss (2012) also reported low level of awareness among faculty members at the Petroleum Institute (PI) in Malaysia.

\section{Sources of Awareness of IR for Students}

The study also sought to identify the different sources through which the respondents first heard about the IR. The data is presented in Table 2 below. 
Table 2: Sources of Awareness of IR for Students

\begin{tabular}{llcc} 
& & Frequency & Percent $(\%)$ \\
\hline & Colleague & 5 & 6 \\
& Lecturer & 10 & 12 \\
& Library & 24 & 28 \\
& Internet & 46 & 52 \\
Total & & & 100 \\
& & &
\end{tabular}

Source: Field survey, 2019

Table 2 indicates that majority of the respondents $46(54.1 \%)$ first heard of the IR by browsing through the internet. This was followed by 24(28.2\%) who first heard of it through the library. Ten (12\%) of the respondents first heard of the IR through a lecturer whilst 5(6\%) heard of it through a colleague student. This could also be attributed to the lack of orientation or awareness creation programmes by the library for graduate students.

Table 3: Purpose for Using the Institutional Repository

\begin{tabular}{lcc}
\hline & Frequency & Percent \\
\hline To access thesis and dissertations & 64 & 75 \\
Search for journal articles & 18 & 21 \\
Search for all kinds of information & 3 & 4 \\
Total & 85 & 100 \\
\hline
\end{tabular}

Source: Field survey, 2019

The current study sought to examine the main purpose for which respondents used the IR.

An examination of Table 3 shows that the majority $75 \%$ of graduate students use the IR to access thesis and dissertations whilst 21 percent of them use the IR mainly to search for journal articles. Only 3 respondents representing 4 percent indicated that they use the IR to search for all kinds of information This finding is similar to the findings of Abdelrahman (2017) who in a study of graduate students at the University of Khartoum reports that students mainly use the IR to access ETDs and ebooks. Similarly, in a study at the Loughborough University, Pickton and McKnight (2006) found that students were more interested in having access to complete theses, post prints and conference papers.

Finally, majority of the respondents agreed with the statement that "IR helps me to accomplish task more efficiently".

\section{Frequency of IR Usage}

The current study sought to examine the main purpose of the respondents for using the IR. Responses on the frequency of using the IR were given based on four statements. The results obtained are displayed in Table 4. 
Table 4: Frequency of IR usage

\begin{tabular}{|l|c|c|}
\hline Statement & Students(n=85) \\
\hline & Frequency & Percent \\
\hline At least once every two weeks & 14 & 16.5 \\
\hline At least once a month & 32 & 37.5 \\
\hline Whenever I need to & 28 & 33 \\
\hline Never & 7 & 100 \\
\hline Total & 85 & \\
\hline
\end{tabular}

Source: Field Survey, 2019

Out of the 85 respondents $32(37.5 \%)$ of the respondents use the IR once a month, 28(33\%) of them indicated that they use the IR whenever they need to, 14(16.5\%) of them indicated they use it at least once every two weeks and 7(8\%) indicated they never use it. It was therefore discovered that the majority of the graduate students use the IR at least once a month. The implication is that they use the IR occasionally. This finding is supported by Nunda and Elia (2019) who studied the use of institutional repositories by postgraduates of Muhimbili University of Health and Allied Sciences and Sokoine University of Agriculture in Tanzania and found that the respondents use the IR occasionally.
The frequency of use which is the actual use could be said to be influenced by the behavioural intention which is also determined by the factor of Perceived Ease of Use (PEOU) of the IR. If users visit the IR and find it easy to use they will continue to use it. However, if users find the IR cumbersome or difficult to use, they will stop its usage.

\section{Level of Satisfaction}

The questionnaire was also designed to solicit data on the level of satisfaction of participants with regard to the utilization of the IR. The results are presented in Table 5.

Table 5: Level of Satisfaction

\begin{tabular}{|l|c|c|}
\hline Statement & Frequency & Percent \\
\hline Very Useful & 21 & 25 \\
\hline Useful & 21 & 25 \\
\hline Somehow Useful & 14 & 16 \\
\hline Not Useful & 29 & 34 \\
\hline Total & 85 & 100 \\
\hline
\end{tabular}

Source: Field survey, 2019 
Table 5 shows the responses of students concerning how useful the IR has been to them. The data reveals that majority of the respondents $(66 \%)$ found the IR very useful, just useful or somehow useful to them. Only $34 \%$ indicated the IR was not useful to them.

\section{Table 6: Benefits of Institutional Repository (IR) to Students}

\begin{tabular}{lccccc}
\hline Statement & SD & DA & N & A & SA \\
\hline $\begin{array}{l}\text { IR enhances learning } \\
\text { and innovation }\end{array}$ & $0(0 \%)$ & $0(0 \%)$ & $0(0 \%)$ & $46(54.2 \%)$ & $39(45.8 \%)$ \\
$\begin{array}{l}\text { I have access to electronic thesis and } \\
\text { dissertations }\end{array}$ & $0 \%$ & $14(16.7 \%)$ & $0(0 \%)$ & $50(58.3 \%)$ & $21(25 \%)$ \\
$\begin{array}{l}\text { I have access to journal articles authored } \\
\text { by UDS lecturers }\end{array}$ & 0 & $14(16 \%)$ & 0 & $21(25 \%)$ & $50(59 \%)$ \\
$\begin{array}{l}\text { IR helps me to accomplish task } \\
\text { more efficiently }\end{array}$ & $8(9 \%)$ & 0 & 0 & $43(51 \%)$ & $34(40 \%)$ \\
IR helps to improve the quality of my work & 0 & $14(16 \%)$ & 0 & $21(25 \%)$ & $50(59 \%)$
\end{tabular}

Source: Field Survey, 2019

Five statements on the benefits of IR to the student were posed to examine the degree to which the student respondents agreed with them. Table 6 shows that majority of the respondents (54.2\%) agreed with the statement that "IR enhances learning and innovation" while $45.8 \%$ of them strongly agreed to it. No respondent was undecided. Also, no respondent disagreed with the statement.

Eighty-three percent of the respondents agreed to the statement that the IR gives them access to electronic theses and dissertations" while $16.7 \%$ of them disagreed to the statement. None of the respondents was undecided or strongly disagreed to the statement.
It is also evident from Table 6 that the statement "I have access to journal articles authored by UDS lecturers" was strongly agreed to by majority (59\%) of the respondents, $(25 \%)$

\section{Challenges facing students in the use of the IR}

The researcher in order to examine the challenges facing students in their use of the IR provided statements to which the respondents were to indicate their level of agreement or disagreement to the statements. Strongly Disagree (SD) Disagree (DA) Neutral (N) Agree (A) Strongly Agree (SA). 
Table 7: Challenges of IR

\begin{tabular}{llllll}
\hline Statement & SD & DA & N & A & SA \\
\hline Lack of awareness creation about IR & - & - & - & $52(61 \%)$ & $33(39 \%)$ \\
Inadequate or erratic power supply & - & - & - & $49(58 \%)$ & $36(42 \%)$ \\
Insufficient technological skills & $43(51 \%)$ & $27(32 \%)$ & - & $8(9 \%)$ & $7(8 \%)$ \\
Inadequate ICT connectivity & - & $10(12 \%)$ & - & $43(51 \%)$ & $32(37 \%)$ \\
and infrastructure & & & & & \\
Insufficient information provided by IR & - & - & - & $45(53 \%)$ & $40(47 \%)$ \\
\hline
\end{tabular}

Source: Field survey, 2019

The participants were asked to indicate the extent to which the lack of knowledge or awareness creation about IR" affects their use of the IR. The majority (52:61\%) agreed that this hindered their utilization of the IR whilst $33(39 \%)$ strongly agreed to it. No respondent took a neutral stance and no respondent disagreed or strongly disagreed to the statement.

On whether inadequate or erratic power supply was a challenge $49(58 \%)$ respondents agreed to the statement whilst 36(42\%) respondents strongly agreed to it. None of the participants was undecided and no respondent disagreed or strongly disagreed to the statement.

Another statement to probe the technological skills of students against the use of the IR was strongly disagreed to by $43(51 \%)$ of the respondents, $27(32 \%)$ disagreed to it whilst none of the respondents took a neutral stance. However, $8(9 \%)$ agreed to the statement. In the same vein, 7(8\%) respondents strongly agreed to the statement.

The statement "Inadequate ICT connectivity and infrastructure" was agreed to by majority of the respondents.

\section{Challenges}

It was discovered that majority of the respondents agreed that "Inadequate or erratic power supply" was a challenge confronting user of the IR. This finding is in line with the finding of Boufarss (2010) who in a study of the development of IRs in Nigeria found erratic power supply as one of the impediments to the development of IRs.

The study also discovered inadequate ICT connectivity and infrastructure as a major challenge confronting the users of the IR. This finding is in tandem with the findings of Boufarss (2010) who found the lack of ICT infrastructure and facilities in institutional repositories as a challenge in Nigeria.

\section{Conclusion}

This study provides empirical evidence on the perception of graduate students on their use of the IR especially in relation to the IR of the UDS. The findings show that majority of the graduate students are aware of the IR but are not making efficient use of it. This could be attributed to challenges graduate students face such as ICT connectivity, infrastructure and erratic power supply. These challenges must not be allowed to hamper the efficient utilization of the IR in enhancing, teaching, learning and research at the University for Development Studies, Tamale. In an era where IRs must contend with shrinking budgets and academic social networks it is only imperative that IRs take measures to overcome the challenges affecting their full utilization.

\section{Recommendations}

The basic philosophy is that graduate students with enhanced access to information will lead to quality research output. To address the low utilisation of IR 
by graduate students some strategic measures

should be taken to influence their use by

implementing the following recommendations.

\section{Orientation for Graduate Students}

Library orientation should be organised for graduate students in order to educate them on the benefits of using the IR for their studies especially in doing research. The use of workshops could help equip students with the skills that would make it easy for them to search the IR efficiently and effectively for scientific and scholarly information.

Do-It-Yourself (DIY) short videos could be put on the IR interface and the Library website to guide students on how to use the IR.

The IR needs the cooperation of the various departments and the university management to be able to succeed. Every effort should be put in place to achieve this goal.

\section{Provision of ICT infrastructure}

The IR relies on the internet to function. The challenge has always been the low bandwidth which makes retrieval of documents very slow. Management should ensure that service providers increase the bandwidth to the various campuses of the University. There is also the need to increase the number of computers in the Library so that as many users as possible would have easy access to upload or download from the institutional repository.

\section{Provision of Electric Power Generators}

The lack of standby electric power generators on all the campuses was a challenge to the users of the IR. Management should give this the necessary attention that it deserves and get the plants installed as a matter of urgency. It must be put on record that at the time of this study the Library was in the process of installing a plant on both the Nyankpala and Tamale Campuses which implies two more campuses (Wa and Navrongo) are to be taken care of in future.

\section{References}

Abdelrahman, O. H. (2017). Use of the University of Khartoum Institutional Repository by
Graduate Students. DESIDOC Journal of Library \& Information Technology, 37(2): 104-108.

Boufarss, M. (2010). If we build it, will they come. In Proceedings of the SLA-Arabian Gulf Chapter 16th Annual Conference.

Davis, F. D., Bagozzi, R. P., \& Warshaw, P. R. (1989). User acceptance of computer technology: a comparison of two theoretical models. Management science, 35(8): 9821003.

Dhanavandan, S. and Tamizhchelvan, M. (2013) A critical study on attitude and awareness of institutional repositories and open access publishing. Journal of Information Science Theory and Practice 1: 67-75.

Dlamini, N. N., and Snyman, M. (2017). Institutional repositories in Africa: obstacles and challenges. Library Review, 66(6/7): 535-548.

Dulle, F. W. (2011). The adoption of open access scholarly communication in Tanzanian public universities: some influencing factors. Mousaion, 29(1): 112-135.

Kim, J. (2007). Motivating and impeding factors affecting faculty contribution to institutional repositories. Journal of digital information, 8(2): 1-11.

Lee, Y., Kozar, K. A., \& Larsen, K. R. (2003). The technology acceptance model: Past, present, and future. Communications of the Association for information systems, 12(1), 50.

Mammo, Y., and Ngulube, P. (2015). Academics' use and attitude towards open access in selected higher learning institutions of Ethiopia.Information development, 31(1): 13-26.

Manchu, O., and Vasudevan, T. M. (2018). Awareness of Institutional Repositories and Open Access Publishing Among Researchers in University of Calicut. International Research: Journal of Library and Information Science, 8(1): 43-51. 
Mnzava, E. E., and Chirwa, M. N. (2018). Usage of Sokoine University of Agriculture Institutional Repository among academic staff at the College of Veterinary Medicine and Biomedical Science in Tanzania. Global Knowledge, Memory and Communication, 67(8/9): 510-522.

Moseti, I. (2016). Digital preservation and institutional repositories: case study of universities in Kenya. Journal of the South African Society of Archivists, 49: 137-154.

Nunda, I., and Elia, E. (2019). Institutional repositories adoption and use in selected Tanzanian higher learning institutions. International Journal of Education and Development using ICT, 15(1). Retrieved July $\quad 19, \quad 2019 \quad$ from https://www.learntechlib.org/p/209740/.

Okite-Amughoro, F. A., Makgahlela, L., \& Bopape, S. (2014). The use of electronic information resources for academic research by postgraduate students at Delta State University, Abraka, Nigeria. South African Journal of Libraries and Information Science, 80(2): 23-37.

Okoroma, F. N. (2018). Awareness, knowledge and attitude of lecturers towards institutional repositories in university libraries in Nigeria. Digital Library Perspectives.

Pickton, M., and McKnight, C. (2006). Research students and the Loughborough institutional repository. Journal of librarianship and information science, 38(4); 203-219.

Ratanya, F. C. (2017). Institutional repository: access and use by academic staff at Egerton University, Kenya. Library Management, 38(4/5): 276-284.

Saulus, N., and Mutula, S. (2019). Faculty's and postgraduate students' awareness of and attitudes to using the institutional repository: the case of the University of Swaziland. Mousaion, 37(3): 1-20.

Thompson, E. S., Akeriwe, M. L., \& Aikins, A. A. (2016). Communicating the Value of an Institutional Repository: Experiences at
Ghana's University for Development Studies. New Review of Academic Librarianship, 22(23): 325-336. 